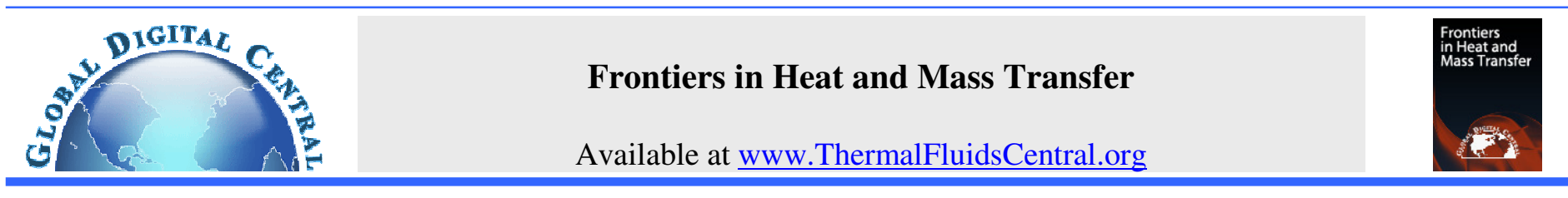

\title{
SUPERSONIC CONDENSATION CHARACTERISTICS OF CO2 IN NATURAL GAS UNDER DIFFERENT TEMPERATURE CONDITIONS
}

\author{
Huan Zheng ${ }^{\mathrm{a}, *}$, Yuliang $\mathrm{Ma}^{\mathrm{b}}$, Huaping $\mathrm{Mei}^{\mathrm{c}}$, Xiaohong $\mathrm{Xu}^{\mathrm{a}}$, Xiguang Chen ${ }^{\mathrm{d}}$, Xunchen $\mathrm{Cao}^{\mathrm{e}}$

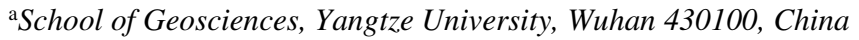 \\ ${ }^{\mathrm{b}}$ Research Institute of Exploration and Development PetroChina Liaohe Oilfield Company, Panjin 124000, China \\ ${ }^{\mathrm{c}}$ The Fifth Gas Production Plant, Changqing Oilfield Company, PetroChina, Xi'an 710018, China \\ ${ }^{\mathrm{d}}$ PetroChina Hangzhou Institute of Petroleum Geology, Hangzhou 310023, China \\ ${ }^{\mathrm{e}}$ Petroleum Exploration and Development Institute, PetroChina Xinjiang Oilfield Company, Karamay 834000, China
}

\begin{abstract}
The supersonic separator has proved to be an effective method to condense and separate $\mathrm{CO}_{2}$ from natural gas, and the inlet temperature plays a vital role on condensation characteristics of $\mathrm{CO}_{2}$ in the supersonic separator due to the instability temperature of wellhead natural gas. In this paper, the physical and mathematical models for the supersonic condensation process of $\mathrm{CO}_{2}$ in the natural gas were established on the basis of $\mathrm{CO}_{2}$ droplet surface tension, nucleation and growth model. The flow and condensation parameters were investigated under different temperature conditions. The results show that when the inlet gas pressure is $8.0 \mathrm{MPa}$, the inlet gas temperature is $280 \mathrm{~K}$ and the $\mathrm{CO}_{2}$ content is 0.15 , the condensation position is $x=240.25$ mm, the maximum nucleation rate is $1.14 \times 10^{21} \mathrm{~m}^{-3} \cdot \mathrm{s}^{-1}$, the maximum droplet radius is $2.146 \times 10^{-7} \mathrm{~m}$, the maximum droplet number is $8.20 \times 10^{14} \mathrm{~kg}^{-1}$, and the maximum humidity is 0.0446 . The decrease of inlet temperature makes the droplet reach a greater growth rate and a larger radius of droplet at nucleation. With the decrease of the inlet temperature, the condensation position moves forward, the maximum nucleation rate and the droplet number, the droplet radius and the humidity of $\mathrm{CO}_{2}$ increase.
\end{abstract}

Keywords: $\mathrm{CO}_{2}$, Natural gas, Laval nozzle, Condensation, Temperature

\section{INTRODUCTION}

Most of the natural gas contains excessive $\mathrm{CO}_{2}$ when extracted from the wellhead. If the $\mathrm{CO}_{2}$ cannot be removed from natural gas, the quality of the natural gas will be affected and the pipeline will be corroded and destroyed. Therefore, $\mathrm{CO}_{2}$ gas must be removed to meet storage and transportation requirements. Conventional $\mathrm{CO}_{2}$ removal technologies such as absorption, adsorption, cryogenic separation, and membrane play a positive role and have been widely used in the field of petroleum industry. However, the conventional natural gas processing has proven both costly and complex, requiring large facilities with high operating expenses, and even could cause environment problem (James and Armin, 2007; Chen et al., 2015).

The supersonic separator combines expansion cooling and centrifugal separation in a single compact device with no chemicals requirement, which has widely used for natural gas dehydration and heavy hydrocarbon removal. It is mainly composed of three sections: the Laval nozzle, the long tube integrated with a cyclone, and the diffuser (Liu et al., 2017), as shown in Fig. 1. In the Laval nozzle, the mixture gas adiabatically expands, velocity increases and temperature drops, to promote the condensable gas with formation of droplets. After that, centrifugal effects generated by the cyclone drive the droplets towards the wall of the long tube. Condensed liquid droplets are separated from main gas flow. The remaining dry gas stream flows into the diffuser in which most of the initial pressure is recovered. Compared to the traditional processing, this new device has no moving parts, which ensuring its high reliability and availability. In addition, the supersonic velocity results in an extremely short residence time of the gas-liquids mixture prevents hydrate problems and eliminates the need for chemicals and associated regeneration systems. Therefore, the supersonic swirling separation technology is suited for unmanned operations, e.g., for the oil and gas field in the offshore, desert and remote areas.

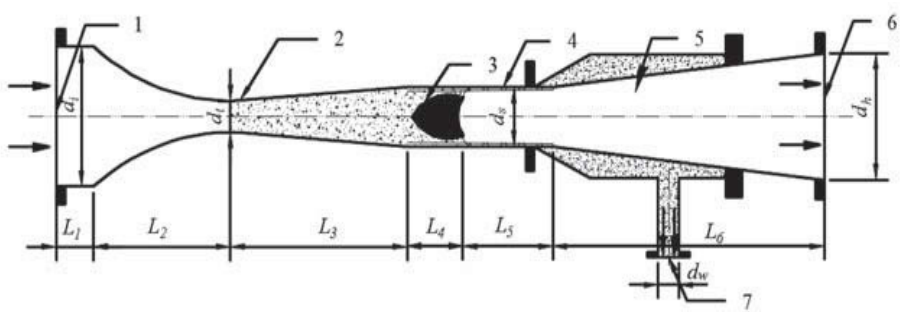

1-Saturated feed gas inlet;2-Laval Nozzle;3-swirling flow generator; 4straight tube; 5-diffuser section; 6-dry gas outlet; 7-wet gas and slip-gas outlet

Fig. 1 Schematic diagram of the supersonic separator.

In the last few years, some scientific research has focused on structural improvement and condensation process in the supersonic separator. Jassim et al. (2008a and 2008b) and Karimi and Abdi (2009) employed a Laval nozzle to study the single phase flow behavior of natural gas under high pressures. The effects of the nozzle geometry and operating parameters on the flow structure were analyzed using the computational fluid dynamics (CFD) approach. Malyshkina (2008a and $2008 \mathrm{~b}$ ) used the two-dimensional Euler model to study the efficiency of the purification of natural gases. Wen et al. (2011 and 2012) optimized the swirling device and diffuser to investigate flow characteristic, and simulated particle flow numerically in supersonic separator. Xiao et al.

*Corresponding author. Email: $865651148 @ q q . c o m$ 
(2017) carried out a numerical study the condensing flow characteristics of water vapor in wet natural gas within the Laval nozzle. Bian et al. (2016, 2018a and 2018b) and Jiang et al. (Jiang et al., 2016a) carried out comprehensive research on a newly designed separator, they improved the separator by reducing the expand angle and extending the length of expanding section. Additionally, studies of the supersonic flow and liquefaction process of heavy hydrocarbon component and natural gas in nozzle are also conducted by them.

In recent years, the supersonic separator has been applied to the field of $\mathrm{CO}_{2}$ removal from natural gas. Bian et al. (2018c) and Jiang et al. (Jiang et al., 2018) investigate the condensation process of $\mathrm{CH}_{4}-\mathrm{CO}_{2}$ mixture gas and supersonic separation mechanism applying the Discrete Particle Method. In the actual production, due to the instability temperature of wellhead natural gas, the inlet temperature plays a vital role on the separation process of $\mathrm{CO}_{2}$ in the supersonic separator. However, there is a lack of studies on the effects of inlet temperature on the condensation characteristics of $\mathrm{CO}_{2}$ and the condensation characteristics are still not clear. Therefore, in this work, the physical and mathematical models for the supersonic condensation process of $\mathrm{CO}_{2}$ in the natural gas were established on the basis of $\mathrm{CO}_{2}$ droplet surface tension, nucleation and growth model. On this basis, the effects of inlet temperature on the flow and condensation parameters were investigated.

\section{MATHEMATICAL MODEL FOR SUPERSONIC CONDENSATION PROCESS}

\subsection{Condensation and Surface Tension Model}

Assuming that $\mathrm{CO}_{2}$ is still in the liquid state when the temperature is lower than the triple point (In fact, $\mathrm{CO}_{2}$ is solid under that circumstance, the separation is much easier to achieve). Girshick and Chiu (1990) and Girshick (1991) proposed classic nucleation theory (CNT) model and internally consistent classical nucleation theory (ICCT) for the droplet condensation process, the studies by Rudek (1996) show that the ICCT is more accurate than the CNT model, so the ICCT model proposed by Girshick is applied to calculate the nucleation rate in this work. The model is described as follows:

$$
J=\frac{1}{S} \frac{\rho_{\mathrm{v}}{ }^{2}}{\rho_{1}} \sqrt{\frac{2 \sigma}{\pi m_{\mathrm{o}}{ }^{3}}} \exp \left(-\frac{16 \pi \sigma^{3}}{3 k_{B} \rho_{1}^{2} R_{\mathrm{M}}{ }^{2} T^{2} \ln ^{2} S}\right) \exp (\theta)
$$

Where, $J$ is the droplet nucleation rate; $S$ is the gas supersaturation; $\rho_{v}$ is the density of the mixed gas; $\rho_{1}$ is the density of the liquid droplets; $\sigma$ is the droplet surface tension; $m_{\mathrm{o}}$ is the single molecular mass; $k_{\mathrm{B}}$ is the Boltzmann constant, $1.38 \times 10^{-23} \mathrm{~J} / \mathrm{K} ; R_{\mathrm{M}}$ is the gas constant; $T$ is the temperature of the mixture gas; $\theta$ is dimensionless surface tension.

Gyarmathy's model (1996) is employed to calculate the growth rate of droplets, which can be described by Eq. (2).

$$
\frac{d r_{\mathrm{d}}}{d t}=\frac{\lambda_{\mathrm{v}}\left(1-\frac{r_{\mathrm{c}}}{r_{\mathrm{d}}}\right)\left(T_{\mathrm{s}}-T\right)}{\rho_{\mathrm{l}} h_{\mathrm{lv}} r_{\mathrm{d}}\left(1+\frac{2 \sqrt{8 \pi}}{1.5 \operatorname{Pr}_{\mathrm{v}}} \frac{\gamma}{\gamma+1} \mathrm{Kn}\right)}
$$

where, $r_{\mathrm{c}}$ is the critical radius of the droplet; $r_{\mathrm{d}}$ is the droplet radius; $T_{\mathrm{s}}$ is the saturation temperature of vapor.

The droplet radius is very small (approximately $10^{-9} \mathrm{~m}$ ) in the droplet growth process and the contact probability with other droplets is very low, so the collision and coalescence between different droplets is ignored in the above models.

The calculation formula of $\mathrm{CO}_{2}$ surface tension prediction model is calculated by the piecewise function method proposed in the literature (Jiang et al., 2016b). The function combined Pitzer correlation, ZuoStenby correlation, Block correlation, Quinn correlation, Miqueua correlation and so on. The average deviation of the piecewise function is only $0.95 \%$ compared with the experimental data, which can achieve an accurate prediction of the surface tension of the liquid $\mathrm{CO}_{2}$.

\subsection{Governing Equations}

The formation diameter of liquid droplets is very small as mentioned above, so the slip velocity between the vapor and $\mathrm{CO}_{2}$ droplet is ignored in this paper when the governing equations are established. The vapor flow characteristics in the nozzle are depicted by partial differential equations, including a continuity equation, a momentum equation, and an energy equation, defined as Eqs.(4)-(6). A continuity equation, a droplet number density conservation equation, and a relation about droplet radius, droplet number and humidity are employed to describe the flow characteristics of liquid, presented as Eqs.(7)-(9).

$$
\begin{gathered}
\frac{\partial \rho_{\mathrm{v}}}{\partial t}+\frac{\partial}{\partial x_{j}}\left(\rho_{\mathrm{v}} u_{j}\right)=S_{\mathrm{m}} \\
\frac{\partial}{\partial t}\left(\rho_{\mathrm{v}} u_{i}\right)+\frac{\partial}{\partial x_{j}}\left(\rho_{\mathrm{v}} u_{j} u_{i}\right)=-\frac{\partial p_{\mathrm{v}}}{\partial x_{i}}+ \\
\frac{\partial}{\partial x_{j}}\left[\mu\left(\frac{\partial u_{j}}{\partial x_{i}}+\frac{\partial u_{i}}{\partial x_{j}}-\frac{2}{3} \delta_{i j} \frac{\partial u_{j}}{\partial x_{j}}\right)\right]+\frac{\partial}{\partial x_{j}}\left(-\rho_{\mathrm{v}} \overline{u_{i}^{\prime} u_{j}^{\prime}}\right)+S_{\mathrm{u}} \\
\frac{\partial}{\partial t}\left(\rho_{\mathrm{v}} E\right)+\frac{\partial}{\partial x_{j}}\left(\rho_{\mathrm{v}} u_{j} E+u_{j} p_{\mathrm{v}}\right)=\frac{\partial}{\partial x_{j}}\left(k_{\mathrm{eff}} \frac{\partial T}{\partial x_{j}}+u_{i} \tau_{\mathrm{eff}}\right)+S_{\mathrm{h}} \\
\frac{\partial}{\partial t}\left(\rho_{\mathrm{v}} E\right)+\frac{\partial}{\partial x_{j}}\left(\rho_{\mathrm{v}} u_{j} Y\right)=S_{\mathrm{Y}} \\
\frac{\partial}{\partial t}\left(\rho_{\mathrm{v}} N\right)+\frac{\partial}{\partial x_{j}}\left(\rho_{\mathrm{v}} u_{j} N\right)=J \\
r_{\mathrm{d}}=\left(\frac{3 Y}{4 \pi \rho_{\mathrm{l}} N}\right)^{\frac{1}{3}}
\end{gathered}
$$

where, $u_{i}$ and $u_{j}$ are axial and radial velocity components; $p$ is the pressure of the mixed gas; $\mu$ is the dynamic viscosity of the mixed gas; $\delta$ is the Kronecker delta; $u_{i}^{\prime}$ and $u_{j}^{\prime}$ are axial and radial velocity fluctuations; $E$ is the total energy; $k_{\text {eff }}$ is the effective thermal conductivity; $\tau_{\text {eff }}$ is the effective stress tensor; $\rho$ is the mixed phase density; $m_{\mathrm{v}}$ is the liquid mass per unit volume condensation in unit time; $h$ is the total enthalpy of gas; $h_{\mathrm{g}}$ is the latent heat of condensation.

The $S_{\mathrm{m}}, S_{\mathrm{u}}$, and $S_{\mathrm{h}}$ are the source terms of vapor continuity equation, vapor momentum equation and vapor energy equation due to condensation, added to the governing equations.

$$
\begin{gathered}
S_{\mathrm{m}}=-m_{\mathrm{v}} \\
S_{\mathrm{u}}=-m_{\mathrm{v}} u \\
S_{\mathrm{h}}=-m_{\mathrm{v}}\left(h-h_{\mathrm{lg}}\right)
\end{gathered}
$$

\subsection{Nozzle Structure and Mathematical Model}

The supersonic nozzle used in this work is shown in Fig. 2. The whole length of the nozzle is $275.10 \mathrm{~mm}$, the subsonic convergent section and divergent section are $112.02 \mathrm{~mm}$ and $63.08 \mathrm{~mm}$, respectively. The diameters of the nozzle inlet, outlet and throat are $70 \mathrm{~mm}, 18.26 \mathrm{~mm}$ and $10 \mathrm{~mm}$, respectively. The curve shape of the convergent section uses bicubic curve and the expanding section adopts circular arc plus linear design method.

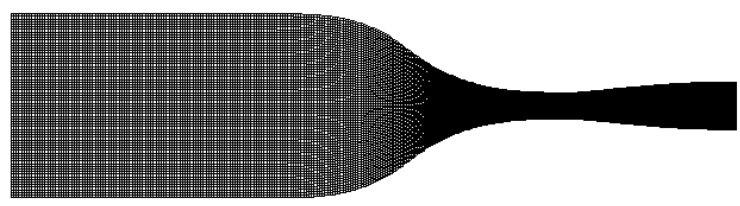

Fig. 2 Grid system for the nozzle. 
With the continuous development of computer science and technology, computational fluid dynamics has been widely used in many subject areas, including heat and mass transfer, chemical engineering and environmental science. The supersonic condensation characteristics of $\mathrm{CO}_{2}$ were calculated using the computational fluid dynamics method.

The unstructured meshes are used for the designed structure of the nozzle. A local mesh encryption method is employed at the boundary layer of the nozzle. The inlet and outlet boundary conditions are set respectively according to the flow characteristics of the supersonic compressible gas in the nozzle. The outlet boundary conditions are set to be pressure outlets.

In addition, the wall is with no-slip, no seepage and adiabatic boundary conditions. The grid independence is verified to ensure the accuracy of the results.

In order to ensure accuracy of simulation results, the convergence criterion for the relative residual of the continuity, momentum, energy and all other dependent variables is assigned as $10^{-9}$.

\subsection{Experimental Verification}

The experimental data of Moses and Stein (1978) are used to test the condensation model and numerical method discussed above. The experimental medium is water vapor. The inlet pressure and temperature are $43.023 \mathrm{kPa}$ and $366 \mathrm{~K}$. The comparison of pressure distribution along the nozzle is presented in Fig. 3. As we can see that the predicted and measured onset of the condensation process is in the vicinity of $x=103 \mathrm{~mm}$, and the numerical results are in good agreement with the experimental data especially in the place where the condensation occurs., which illustrates that the models and methods used to simulate the condensation characteristics are suitable.

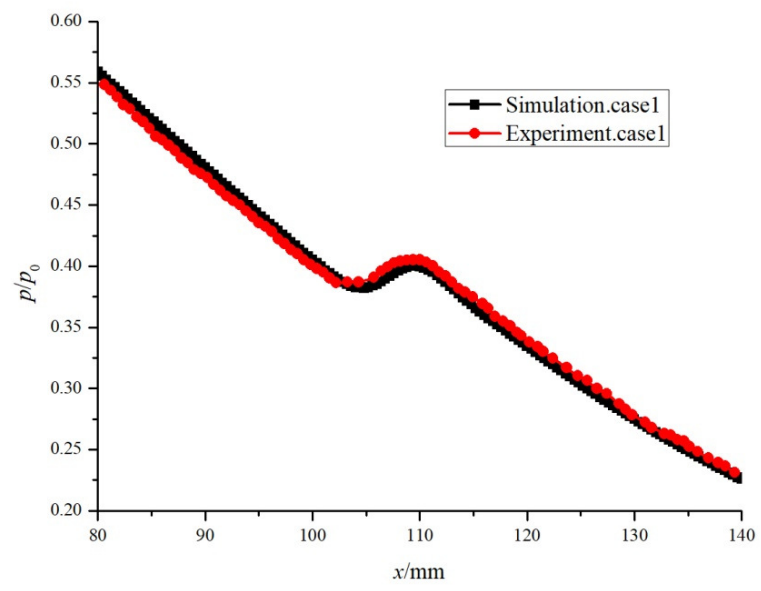

Fig. 3 Comparison between experiment and simulation results in mose's nozzle.

\section{EFFECTS OF INLET TEMPERATURE ON CONDENSATION PROCESS OF $\mathrm{CO}_{2}$ GAS}

The influences of inlet temperature on the condensation parameters are numerically simulated, under the conditions that the inlet pressure and water vapor mass fraction are kept constant $(8.0 \mathrm{MPa}$ and 0.15 , respectively), the inlet temperature is set to be $270 \mathrm{~K}, 275 \mathrm{~K}$ and $280 \mathrm{~K}$, respectively. The flow and condensation parameters distribution (including pressure, temperature, nucleation rate, droplet radius, droplet number humidity, degree of supersaturation and droplet growth rate) in the nozzle were obtained. The results of the simulation are shown in Figs. 4-11.

As we can see from the temperature (Fig.4) and pressure (Fig.5) distribution, when the inlet pressure is $8.0 \mathrm{MPa}$, volume fraction of the $\mathrm{CO}_{2}$ is 0.15 , with the decrease of the inlet temperature, the condensation position of $\mathrm{CO}_{2}$ moves forward, but the outlet pressure increases. When the inlet temperature is $280 \mathrm{~K}$, the condensation position is $x=240.25 \mathrm{~mm}$ and the pressure at outlet is $1.109 \mathrm{MPa}$, while the condensation position moves to forward to $x=226.27 \mathrm{~mm}$ and the pressure reaches $1.322 \mathrm{MPa}$ when the inlet temperature is $270 \mathrm{~K}$. This is because with the decrease of inlet temperature, the degree of supercooling is greater, it is more prone to the realization of condensation. From the pressure distribution we could also see that before the $\mathrm{CO}_{2}$ gas spontaneous condensation occurs, the pressure distribution is essentially in agreement although the inlet temperature is different, which indicating that the change of inlet temperature has little effect on the temperature when there is no condensation occurs. After that, due to the lower temperature condensation requires a smaller supersaturation, the spontaneous condensation occurs earlier when the inlet temperature is lower.

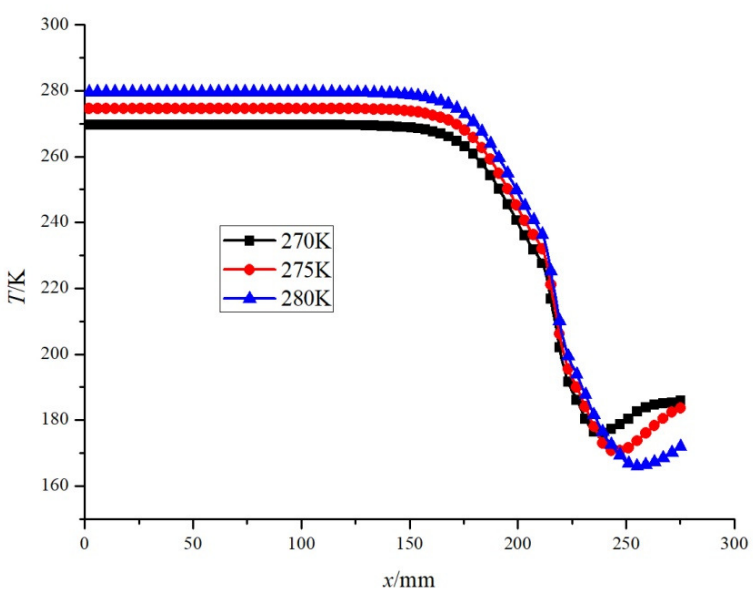

Fig. 4 Temperature distribution in the nozzle.

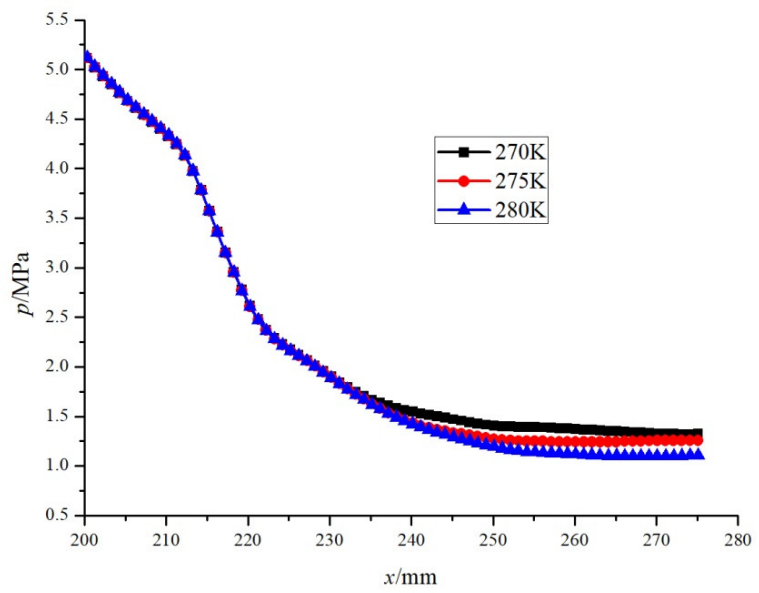

Fig. 5 Pressure distribution in the nozzle.

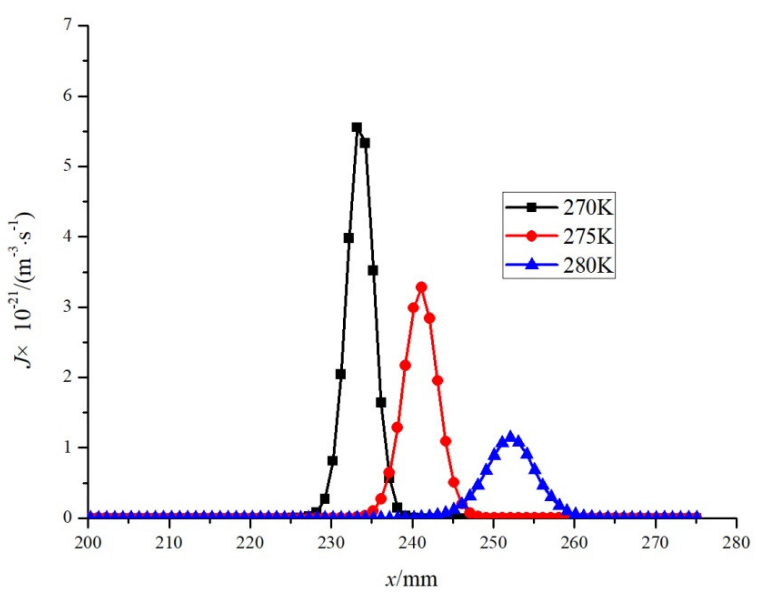

Fig. 6 Nucleation rate distribution in the nozzle. 


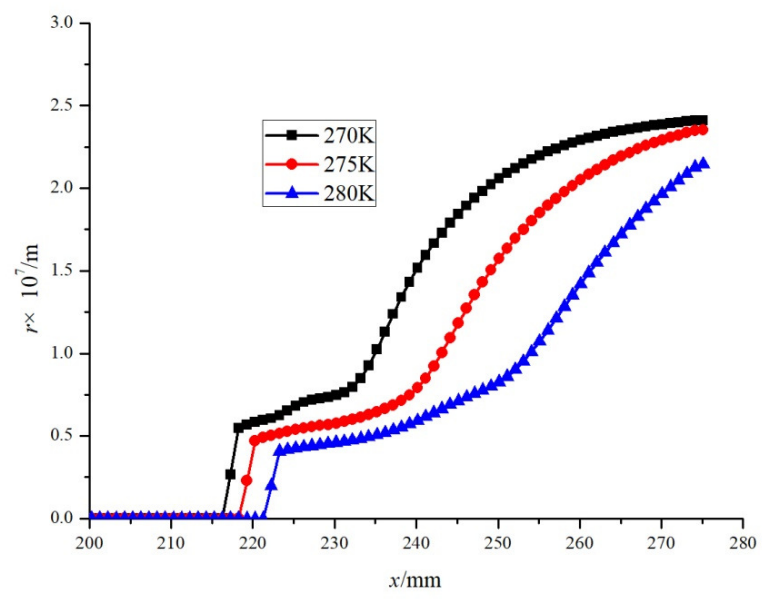

Fig. 7 Droplet radius distribution in the nozzle.

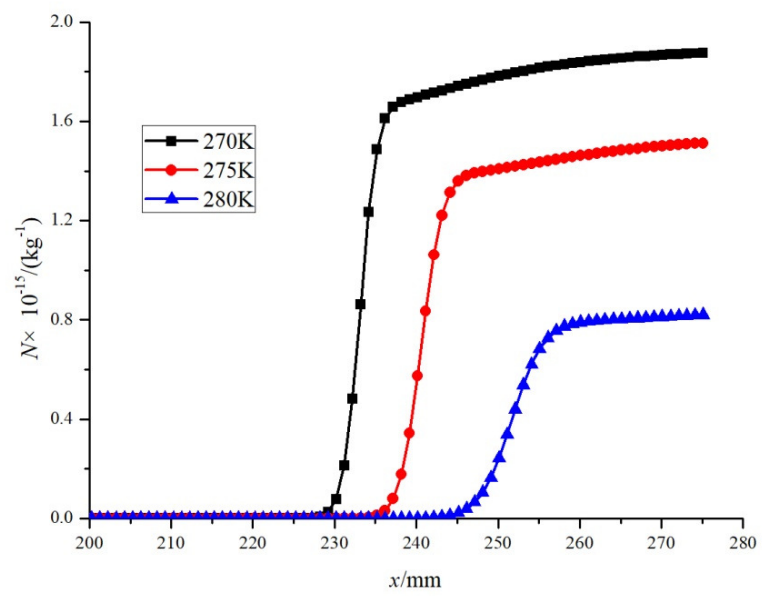

Fig. 8 Droplet number distribution in the nozzle.

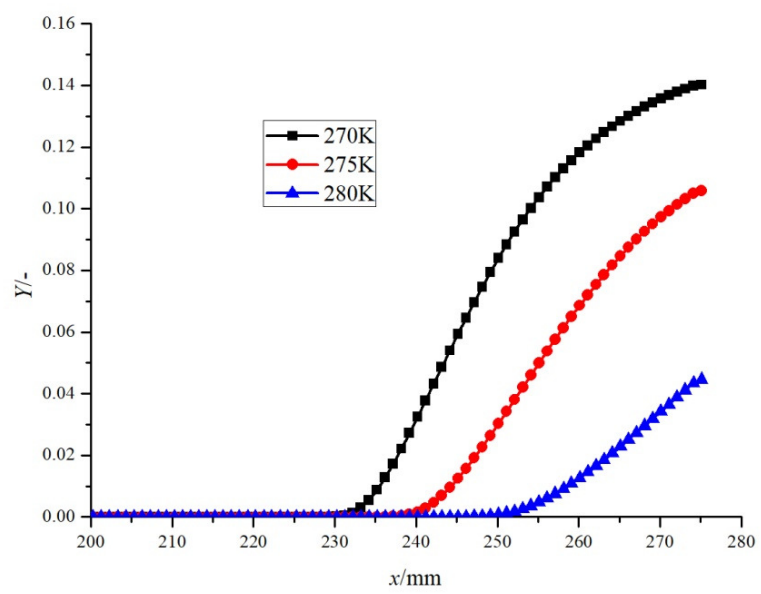

Fig. 9 Humidity distribution in the nozzle.

As we can see from the nucleation rate (Fig.6) and radius (Fig.7) distribution, with the inlet temperature decreases, the maximum nucleation rate and droplet radius increase. When the inlet pressure to $280 \mathrm{~K}$, the maximum nucleation rate is $1.14 \times 10^{21} \mathrm{~m}^{-3} \cdot \mathrm{s}^{-1}$, and the largest droplet radius is $2.146 \times 10^{-7} \mathrm{~m}$. when the inlet temperature decreases to $270 \mathrm{~K}$, the maximum nucleation rate is $5.55 \times 10^{21} \mathrm{~m}^{-3} \cdot \mathrm{s}^{-1}$, and the maximum droplet radius increases to $2.411 \times 10^{-7} \mathrm{~m}$. The reason is that the inlet temperature is lower, the position of condensation occurs is in advance, the temperature is higher when condensation occurs, by the formula (1) we can conclude that the nucleation rate is smaller.
From the droplet number (Fig.8) and humidity (Fig.9) distribution under different temperature conditions we can see, with the decrease of inlet temperature, the droplet number and humidity of $\mathrm{CO}_{2}$ increases gradually. When the inlet temperature is $280 \mathrm{~K}$, the maximum droplet number is $8.20 \times 10^{14} \mathrm{~kg}^{-1}$, the outlet humidity is 0.0446 , but when the inlet temperature decreases to $270 \mathrm{~K}$, the maximum droplet number increases to $1.87 \times 10^{15} \mathrm{~kg}^{-1}$, the outlet humidity increases to 0.1403 .

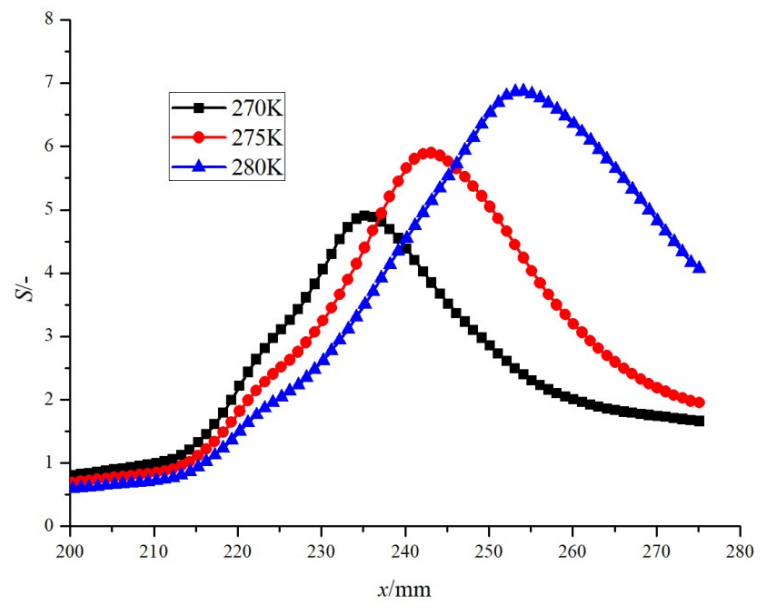

Fig. 10 Degree of supersaturation distribution in the nozzle.

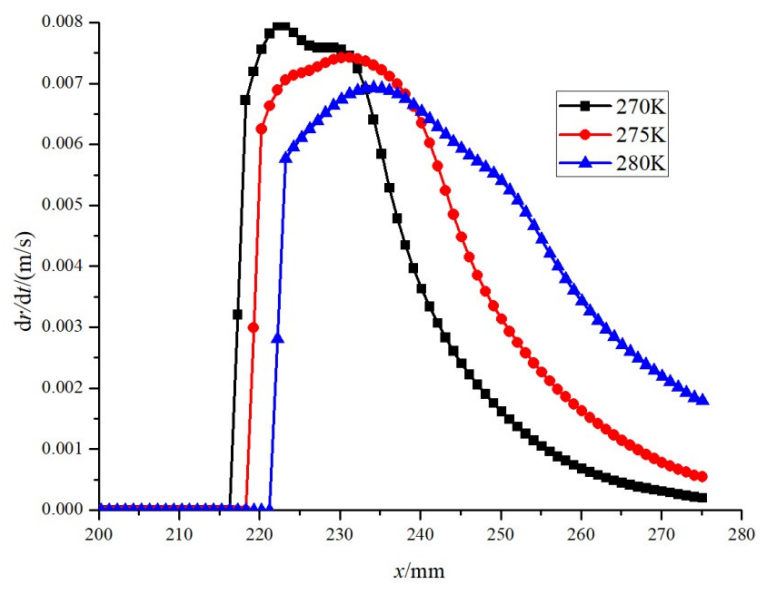

Fig. 11 Droplet growth rate distribution in the nozzle.

It can be seen in combination with all the results, the decrease of inlet temperature makes the droplet reach a greater growth rate and a larger radius of droplet at nucleation. However, as the condensation promotes more condensation heat release, the decrease of the degree of supersaturation and the droplet growth rate are faster, and the droplet radius slows down when the condensation occurs. The reduction of inlet temperature plays a leading role in the promotion of condensation, and greater humidity can be reached at the outlet of the nozzle. When the inlet temperature is $270 \mathrm{~K}$, the outlet humidity of the nozzle is 0.1403 , which is equivalent to $70.15 \%$ of $\mathrm{CO}_{2}$ liquefied, and the mole fraction of $\mathrm{CO}_{2}$ in the outlet gas decreases to 0.0597 .

\section{CONCLUSIONS}

When the inlet gas pressure is $8.0 \mathrm{MPa}$, the inlet gas temperature is $280 \mathrm{~K}$ and the $\mathrm{CO}_{2}$ content is 0.15 , the condensation position is $x=240.25 \mathrm{~mm}$, the maximum nucleation rate is $1.14 \times 10^{21} \mathrm{~m}^{-3} \cdot \mathrm{s}^{-1}$, the maximum droplet radius is $2.146 \times 10^{-7} \mathrm{~m}$, the maximum droplet number is $8.20 \times 10^{14} \mathrm{~kg}^{-1}$, and the maximum humidity is 0.0446 .

The decrease of inlet temperature makes the droplet reach a greater growth rate and a larger radius of droplet at nucleation. However, as the condensation promotes more condensation heat release, the decrease of the degree of supersaturation and the droplet growth rate are faster, and 
the droplet radius slows down when the condensation occurs. The reduction of inlet temperature plays a leading role in the promotion of condensation, and greater humidity can be reached at the outlet of the nozzle.

With the decrease of the inlet temperature, the condensation position moves forward, the maximum nucleation rate and the droplet number, the droplet radius and the humidity of $\mathrm{CO}_{2}$ increase. In the actual production, the condensation of $\mathrm{CO}_{2}$ in natural gas can be promoted by adjusting the inlet temperature, and the liquefaction efficiency of the Laval nozzle will be improved.

\section{ACKNOWLEDGEMENTS}

This study was supported by the National Natural Science Foundation of China (Grant No. 51406257).

\section{NOMENCLATURE}

$a_{0} \quad$ molecular surface area $\left[\mathrm{m}^{2}\right]$

$E \quad$ total energy $\left[\mathrm{J} \mathrm{kg}^{-1}\right]$

$h \quad$ vapor total enthalpy [ $\left.\mathrm{J} \mathrm{kg}^{-1}\right]$

$h_{\mathrm{lg}} \quad$ latent heat of condensation $\left[\mathrm{J} \mathrm{kg}^{-1}\right]$

$J$ spontaneous nucleation rate, $\left[\mathrm{m}^{-3} \mathrm{~s}^{-1}\right]$

$K_{r} \quad$ heat transfer coefficient between the droplet and the

surrounding vapor $\left[\mathrm{J} \mathrm{K}^{-1}\right]$

$k_{\mathrm{B}} \quad$ Boltzmann constant [ $\left.\mathrm{J} \mathrm{K}^{-1}\right]$

$k_{\text {eff }} \quad$ effective thermal conductivity [W $(\mathrm{m} \mathrm{K})^{-1}$ ]

Kn Kundsen number [-]

$l_{2} \quad$ length of expanding section [mm]

$m_{\mathrm{v}} \quad$ liquid mass per unit volume condensation in unit time $\left[\mathrm{kg} \mathrm{m}^{-3}\right.$

$\left.\mathrm{s}^{-1}\right]$

$m_{\mathrm{o}} \quad$ single molecular mass $[\mathrm{kg}]$

$N_{A} \quad$ Avogadro's constant $\left[\mathrm{mol}^{-1}\right]$

$p \quad$ gas pressure $[\mathrm{Pa}]$

$p_{\mathrm{c}} \quad$ critical pressure [bar]

$\operatorname{Pr}_{\mathrm{V}} \quad$ Prandtl number [-]

$r \quad$ radius at arbitrary cross section of $x[\mathrm{~mm}]$

$r_{\mathrm{c}} \quad$ critical radius of droplets, [m]

$r_{\mathrm{cr}} \quad$ radius of the nozzle throat [mm]

$r_{\mathrm{d}} \quad$ Sauter radius of droplets, [m]

$R_{\mathrm{M}} \quad$ gas constant, $\left[\mathrm{J} \mathrm{kg}^{-1} \mathrm{~K}^{-1}\right]$

$S \quad$ degree of supersaturation[-]

$S_{\mathrm{m}} \quad$ vapor continuity equation source term $\left[\mathrm{kg} \mathrm{m}^{-3} \mathrm{~s}^{-1}\right]$

$S_{\mathrm{u}} \quad$ vapor momentum equation source term $\left[\mathrm{kg} \mathrm{m}^{-2} \mathrm{~s}^{-2}\right]$

$S_{\mathrm{h}} \quad$ vapor energy equation source term $\left[\mathrm{J} \mathrm{m}^{-3} \mathrm{~s}^{-1}\right]$

$S_{\mathrm{Y}} \quad$ liquid continuity equation source term $\left[\mathrm{kg} \mathrm{m}^{-3} \mathrm{~s}^{-1}\right]$

$t \quad$ temperature in the current state $\left[{ }^{\circ} \mathrm{C}\right]$

$T \quad$ gas temperature [K]

$T_{\mathrm{c}} \quad$ critical temperature [K]

$T_{\mathrm{s}} \quad$ saturation temperature of vapor [K]

$u \quad$ gas velocity $\left[\mathrm{m} \mathrm{s}^{-1}\right]$

$u^{\prime} \quad$ velocity fluctuation $\left[\mathrm{m} \mathrm{s}^{-1}\right]$

$V_{\mathrm{c}} \quad$ critical volume $\left[\mathrm{m}^{3} \mathrm{~mol}^{-1}\right]$

$v_{1} \quad$ volume of a single droplet $\left[\mathrm{m}^{3}\right]$

$x \quad$ distance between arbitrary cross section and the inlet [mm]

$Y \quad$ humidity [-]

Greek symbols

$\delta \quad$ Kronecker delta [-]

$\mu \quad$ dynamic viscosity of the mixed gas $\left[\mathrm{N} \mathrm{s} \mathrm{m}^{-1}\right]$

$\rho \quad$ mixed phase density $\left[\mathrm{kg} \mathrm{m}^{-3}\right]$

$\rho_{\mathrm{v}} \quad$ mixed gas density $\left[\mathrm{kg} \mathrm{m}^{-3}\right]$

$\rho_{1} \quad$ liquid density $\left[\mathrm{kg} \mathrm{m}^{-3}\right]$

$\sigma \quad$ surface tension of droplets $\left[\mathrm{N} \mathrm{m}^{-1}\right]$

$\sigma_{0} \quad$ liquid surface tension at $0^{\circ} \mathrm{C}\left[\mathrm{N} \mathrm{m}^{-1}\right]$

$\sigma_{\mathrm{r}} \quad$ comparative surface tension when the dual reference fluid

contrast state method is used $\left[\mathrm{N} \mathrm{m}^{-1}\right]$

$\theta \quad$ dimensionless surface tension [-] $\kappa \quad$ Boltzmann constant, $\kappa=1.38 \times 10^{-23}[\mathrm{~J} / \mathrm{K}]$

$\tau_{\text {eff }} \quad$ effective stress tensor [-]

$\varphi \quad$ the expansion angle [degree]

$\lambda_{\mathrm{v}} \quad$ thermal conductivity of the vapor $\left[\mathrm{Wm}^{-1} \cdot \mathrm{K}^{-1}\right]$

$\gamma \quad$ specific heat ratio of the vapor phase [-]

$\omega \quad$ eccentricity factor [-]

\section{REFERENCES}

Bian, J., Jiang, W. M., Teng, L., Liu Y., Wang S. W., and Deng Z. F., 2016, "Structure improvements and numerical simulation of supersonic separators," Chemical Engineering and Processing: Process Intensification, 110 (5), 214-219.

https://doi.org/10.1016/j.cep.2016.10.012

Bian, J., Cao, X. W., Yang, W., Edem M. A., Yin P. B., and Jiang W. M., 2018a, "Supersonic liquefaction properties of natural gas in the Laval nozzle,” Energy 159 (9), 706-715. https://doi.org/10.1016/j.energy.2018.06.196

Bian, J., Cao, X. W., Yang, W., Du H., and Yin P. B., 2018b, "Effects of external particles on the liquefaction property of natural gas in a Laval nozzle," Powder Technology, 339 (11), 894-902. https://doi.org/10.1016/i.powtec.2018.08.077

Bian, J., Jiang, W. M., Hou, D. Y., Liu Y., and Yang J, 2018c, "Condensation characteristics of $\mathrm{CH}_{4}-\mathrm{CO}_{2}$ mixture gas in a supersonic nozzle," Powder Technology, 329 (1), 1-11. https://doi.org/10.1016/j.powtec.2018.01.042

Chen, X. Y., Vinh-Thang, H., Ramirez, A. A., 2015, "Membrane gas separation technologies for biogas upgrading," Rsc Advances, 5 (31), 24399-24448.

https://doi.org/10.1039/c5ra00666j

Girshick, S. L., and Chiu, C. P., 1990, "Kinetic nucleation theory: a new expression for the rate of homogeneous nucleation from an ideal supersaturated vapor," Journal of Chemical Physics, 93 (9), 1273-1277. https://doi.org/10.1063/1.459191

Girshick, S. L., 1991, "Comment on: self-consistency correction to homogeneous nucleation theory," Journal of Chemical Physics, 94 (1), 826-827.

https://doi.org/10.1063/1.460309

Gyarmathy, G., 1982, "The spherical droplet in gaseous carrier streams: review and synthesis," Multiphase Science \& Technology 1 (2), 99-279. https://doi.org/10.1615/MultScienTechn.v1.i1-4.20

James, A. R., and Armin, D. E., 2007, "State-of-the-art adsorption and membrane separation processes for hydrogen production in the chemical and petrochemical industries," Separation Science \& Technology, 42 (6), 1123-1193.

https://doi.org/10.1080/01496390701242194

Jassim, E., Abdi, M. A., and Muzychka, Y., 2008, “Computational fluid dynamics study for flow of natural gas through high-pressure supersonic nozzles: part 1. Real gas effects and shockwave," Petroleum Science and Technology, 26 (15), 1757-1772.

https://doi.org/10.1080/10916460701287847

Jassim, E., Abdi, M. A., and Muzychka, Y., 2008, “Computational fluid dynamics study for flow of natural gas through high-pressure supersonic nozzles: part 2. Nozzle geometry and vorticity," Petroleum Science and Technology, 26 (15), 1773-1785. https://doi.org/10.1080/10916460701304410 
Jiang, W. M., Bian, J., Wu, A., Gao S., Yin P. B., and Hou D. Y., 2018, "Investigation of supersonic separation mechanism of $\mathrm{CO}_{2}$ in natural gas applying the Discrete Particle Method," Chemical Engineering and Processing: Process Intensification, 123 (2), 272-279.

https://doi.org/10.1016/j.cep.2017.11.019

Jiang, W. M., Bian, J., Liu, Y., Liu Z. L., Teng L., and Geng G., 2016a, "Investigation of flow characteristics and the condensation mechanism of ternary mixture in a supersonic nozzle," Journal of Natural Gas Science and Engineering. 34 (15), 1054- 1061.

https://doi.org/10.1016/j.jngse.2016.07.075

Jiang, W. M., Bian, J., Liu, Y., Gao S., Chen M. C., and Du S. L., 2016b, "Modification of the $\mathrm{CO}_{2}$ surface tension calculation model under low-temperature and high-pressure condition," Journal of Dispersion Science \& Technology, 38 (5), 671-676.

https://doi.org/10.1080/01932691.2016.1188399

Karimi, A., and Abdi, M. A., 2009, "Selective dehydration of highpressure natural gas using supersonic nozzles," Chemical Engineering and Processing: Process Intensification, 48 (9), 560-568.

https://doi.org/10.1016/j.cep.2008.09.002

Liu, X. W., and Liu, Z. L., 2017, "Numerical investigation and improvement strategy of flow characteristics inside supersonic separator," Separation Science \& Technology, 53 (4), 940-952.

https://doi.org/10.1080/01496395.2017.1388256

Malyshkina, M. M., 2008, "The structure of gas dynamic flow in a supersonic separator of natural gas," High Temperature, 46 (7), 69-76. https://doi.org/10.1134/s10740-008-1010-5
Malyshkina, M. M., 2008, "The procedure for investigation of the efficiency purification of natural gases in a supersonic separator," High Temperature, 48 (15), 244-250. https://doi.org/10.1134/S0018151X10020161

Moses, C. A., and Stein, G. D., 1978, "On the growth of steam droplets formed in a Laval nozzle using both static pressure and light scattering measurements." Journal of Fluids Engineering, 100 (3), 311.

https://doi.org/ 10.1115/1.3448672

Rudek, M. M., Fisk, J. A., Chakarov, V. M., and Katz J. L., 1996, "Condensation of a super-saturated vapor. Xii. The homogeneous nucleation of the n-alkanes," Journal of Chemical Physics, 105 (4), 4707-4713. https://doi.org/10.1063/1.472312

Wen, C., Cao, X. W., Yang, Y., and Li W. L., 2012a, "Numerical simulation of natural gas flows in diffusers for supersonic separators," Energy 37 (5), 195-200.

https://doi.org/10.1016/j.energy.2011.11.047

Wen, C., Cao, X. W., Yang, Y., and Zhang J., 2012b, "Evaluation of natural gas dehydration in supersonic swirling separators applying the Discrete Particle Method," Advanced Powder Technology, 23 (4), 228233.

https://doi.org/10.1016/j.apt.2011.02.012

Xiao, R., Jin, W., Han, S., Rui L., and Cao X. W., 2017, "Numerical simulation on condensing flow of water vapor of wet natural gas inside the nozzle," Frontiers in Heat \& Mass Transfer, 9, 6, 1-8. http://dx.doi.org/10.5098/hmt.9.6 